\title{
El peso del pasado. Crítica y pintura como mecanismos de construcción histórica. ${ }^{1}$
}

\author{
JuLIÁN Díaz SÁNCHEZ (Facultad de letras UCLM) \\ The weight of the past. Criticism and painting as tools \\ for History construction.
}

RESUMEN

Tanto Ad Reinhardt como Antonio Saura, en lugares y contextos bien diferentes, consideraron el arte abstracto como un mecanismo de salvación del arte. En la España de posguerra, los críticos y los artistas encontraron una línea de continuidad entre las grandes tradiciones pictóricas (de Velázquez a Goya) y el informalismo.

PALABRAS CLAVE: Crítica de arte; Informalismo; Construcción del pasado.
ABSTRACT

Both Ad Reinhardt as Antonio Saura, in very different places and contexts, considered abstract art as a means of salvation of art. In post-war Spain, critics and artists found a line of continuity between the great pictorial traditions (from Velázquez to Goya) and the art informel.

KEYWORDS Critic of Art; Informalism; Building of the Past

\section{DOS VIÑETAS DE AD REINHARDT}

El día 12 de agosto de 1946, la revista Newsweek publicaba una curiosa viñeta firmada por Ad Reinhardt, «El rescate del arte», perteneciente a la serie Las sátiras y los comics artísticos; merece la pena intentar una descripción somera: en el centro se ve a una niña (que lleva la palabra «arte» escrita en un rótulo) en mitad de una vía férrea, en una actitud de confusión; va ser salvada por un joven (que se identifica por las palabras «arte abstracto»), que evitará que la arrolle un tren del que cuelgan unas cintas en las que pueden leerse las palabras «banalidad»,

1 El presente trabajo se vincula al Proyecto de Investigación del Plan Nacional de I+D+i Tras la república. Redes de ida y vuelta en el arte español desde 1931. Ref. HAR 2011-25864 
«prejuicio», «estereotipos lingüísticos», «bebida», «complejos de inferioridad», «corrupción», «avaricia» y «pecado», se trata, sin duda, de los grandes peligros que acechan al arte. Es toda una lección de historia del arte la que imparte, medio en serio medio en broma, Ad Reinhardt, un artista muy preocupado por la historia y por la teoría escrita que había sido discípulo de Meyer Schapiro. El discurso es claro; el arte abstracto, joven, valiente, puro e incorruptible, salvará al Arte (con mayúscula) de los enormes riesgos a los que se enfrenta en ese momento. Da la impresión de que, en 1946, muchas personas lo pensaban seriamente; Peggy Guggenheim, sin ir más lejos, debió suponer algo parecido en 1943 cuando, siguiendo el consejo de Duchamp, encargó a Jackson Pollock una gran pintura mural para su residencia y dejó de frecuentar a los viejos surrealistas. O quienes hicieron que el MoMA y el Instituto de Arte Contemporáneo de Boston abrazaran (éste parece ser el término más adecuado) el arte abstracto en medio de una fuerte polémica².

La viñeta de Reinhardt se inscribe en un modo normalizado de contar la historia del arte, una forma narrativa que contempla el desarrollo histórico como una travesía en la que lo bueno (el arte de verdad) se abre siempre camino y acaba por triunfar, como en sus conocidas y posteriores "Doce reglas" ${ }^{3}$, en las que se defiende la pureza absoluta como único instrumento que puede salvar al arte de los grandes peligros que son el academicismo y la sumisión al mercado.

Algo más de dos meses antes, el 2 de junio de 1946, la revista PM publicaba otra viñeta del mismo autor, Cómo mirar el arte moderno en América, aquí puede verse un gran árbol en cuyo tronco aparecen los nombres de Braque, Matisse y Picasso, las raíces (Cezanne, Seurat, Gauguin y van Gogh) surgen de un suelo donde se menciona a Monet, Manet y Poussin junto a epígrafes como «arte griego», «primitivo» y «polinesio». Las hojas del árbol contienen los nombres más variados (menos notorios, menos famosos), una de las ramas está algo resquebrajada a causa de unos pesos que representan la influencia del arte mexicano, los artistas durante la segunda guerra mundial, la ilustración regionalista, la naturaleza muerta. De esa rama penden hojas que corresponden a pintores figurativos, pero el tronco ha dado lugar a otras tres que crecen fuertes y seguras, en la del centro, aparecen los nombres de Gorky, Tobey, Motherwell, Rothko, imposible atender a todos los detalles, pero hay uno interesante, la hoja de Matta se ha desprendido y vuela ¿hacia el olvido? ¿por motivos exclusivamente artísticos?

Se trata de un panorama muy abigarrado, que necesita del manual de instrucciones que Ad Reinhardt ha incluido, en él se explica que el árbol es una guía del mundo del arte con opciones que van de la pintura pura a las imágenes de

2 GULBAUT, Serge, «La aterradora libertad del pincel. El Instituto de Arte contemporáneo de Boston y el arte moderno» (1985), Sobre la desaparición de ciertas obras de arte, Cuernavaca, Curare, 1995.

3 REINHARDT, Ad. «Doce reglas para una nueva academia» (1957), reproducido en MARCHÁN FIZ, Simón, Del arte objetual al arte de concepto, Madrid, Akal, 1982. 
masas, en la que el lector puede elegir según sus preferencias (las del autor están muy claras), incluso facilita unas hojas en blanco que pueden rellenarse y pegarse en caso de que el usuario no encuentre sus artistas u opciones favoritas, es, por tanto una lección abierta que puede completarse a gusto del espectador-consumidor.

Sabemos que Reinhardt guardó cuidadosamente los collages que originaron estas obras, a las que debió conceder importancia 4 . Igual que en la viñeta anterior, aquí hay un modelo historiográfico reconocible, el arborescente, donde una propuesta artística va dando lugar a la siguiente y hay derivaciones, ramas que van haciendo que el árbol sea cada vez más tupido y la representación más complicada. El esquema de Reinhardt se parece al que, más en serio, proponía Alfred H. Barr en el catalogo de la exposición Cubism and Abstract Art, celebrada en 1936 en el MoMA ${ }^{5}$, y que Reinhardt no podía desconocer.

El cuadro de Barr, que se ha reproducido hasta la saciedad, tiene también una disposición arborescente aunque, al contrario que en el de Reinhardt, el presente aparezca en la parte de abajo; la tesis fundamental es que el arte moderno, que nace con Cezanne, Gauguin, el neoimpresionismo y el grabado japonés, desemboca en el arte abstracto tras una importante estación de paso que es el cubismo; contrariamente a algunas visiones originales, que presentan el cubismo como una vuelta de tuerca a lo real, Barr da a entender que es una etapa cualificada en el proceso de abstractización o, si se quiere, de opticalidad. En todo caso, ha de subrayarse, en primer lugar, el hecho de que el arte abstracto aparezca como el final después del que sólo cabe un retroceso. No parece menos interesante la afirmación tácita de que el arte abstracto no pueda explicarse sin tener en cuenta unos antecedentes (es éste el argumento sobre el que ironiza Reinhardt), que tenga que incluir siempre una visión del pasado. No dejaremos de lado el hecho de que algunos artistas han dejado propuestas historiográficas de gran interés, del mismo modo que algunas obras de arte nos han ayudado a entender otras anteriores. Pero no perdamos de vista la primera idea, el arte abstracto posee un cierto poder de salvación.

4 HESS, Thomas B., Los cómics de arte y las sátiras de Ad Reinhardt, México, Alias, 2010.

5 BARR, Alfed, Cubism and Abstract Art, New York, MoMA, 1936, el texto del catálogo y el esquema citado en BARR, Alfred H., La definición de arte moderno, Madrid, Alianza, 1989. GUILBAUT, Serge, Bajo la bomba. El jazz de la guerra de imágenes transatlántica. 1946-1956, Madrid, MACBA, 2007. En esta catálogo, junto al esquema citado, se reproducen unos «Diagramas ‘torpedo' de la colección ideal» (p. 448), realizados por el propio Barr, otro posible modelo historiográfico, muy adecuado para la guerra fría; el primero se inicia con Goya, literalmente aquí, «padre de todo el arte moderno», como proclamó Joaquín Ruiz Giménez en el discurso inaugural de la I Bienal Hispanoamericana de Arte, ambos torpedos terminan en 1950, con el arte de Estados unidos y México, abstracción junto a indigenismo, se supone.

6 ENCINA, Juan de la, El paisaje moderno, México. Universidad de Morelia, 1939. 


\section{SOBRE LOS DIFERENTES USOS DE LA TRADICIÓN}

El primer texto que Ricardo Gutiérrez Abascal, más conocido como Juan de la Encina, director del Museo de Arte Moderno de Madrid, relevante escritor de arte, compuso tras su marcha al exilio fue una conferencia sobre el paisaje moderno; en ella tiene un papel importante la Vista de Toledo (ca. 1600) del Greco, que el crítico había visto, en el Metropolitan Museum de Nueva York, junto a Juan Ramón Jiménez en octubre de 1938. Encina se refiere a la pintura del Greco en términos tan elogiosos como significativos; "es un milagro de pintura. $Y$ tan moderna que, precisamente, está totalmente realizada con los conceptos que han inspirado al paisaje moderno después del paso por el mundo de Cézanne (...) Cosa extraña, ¿verdad?... Pues así es. No crean, siempre, amigos, en las cronologías que fijan los historiadores del arte. Porque suele haber sorpresas como ésta» ${ }^{6}$. Conviene leer despacio la cita (toda la conferencia es muy recomendable) porque Juan de la Encina no dice que el cuadro del Greco sea un antecedente para explicar a Cezanne, sino que los paisajes del Greco y Cezanne comparten los principios de la pintura moderna, que el Greco, por decirlo más claramente, forma parte de la modernidad, y que ésta no es sino una interpretación formal de la tradición; lo explicó en su libro más conocido, La trama del arte vasco (1920), en el que se concede una importancia particular a la emigración de artistas vascos a París en los años del cambio de siglo; allí la escena artística se encuentra algo fascinada por la tradición española, redescubierta a lo largo del siglo XIX. La trama del arte vasco, al fin, es el cruce de esas dos fuerzas en presencia. Leyendo a Juan de la Encina queda claro que habría suscrito algunas afirmaciones de Juan Antonio Gaya Nuño, como la de que «tan descomedido es explicar la obra de Manet sin referirse a Velázquez, como comentar a éste prescindiendo de Manet»" ${ }^{7}$, ello a pesar del maltrato al que el autor de Historia de la crítica de arte en España sometió, en el libro citado, a nuestro crítico. Una afirmación, por cierto, que no está tan alejada de otra de Piero Manzoni que, de nuevo, invita a repensar la historia del arte; «a menudo oímos a alguien hablar de que no comprende el arte contemporáneo, pero que sin embargo ama el arte del pasado. Todo esto se debe a un equívoco fundamental en relación con el propio arte y podemos estar seguros de que las personas que hablan de este modo no entienden nada ni del arte del pasado ni del arte contemporáneo »8.

No hay nada nuevo, ni raro, en el hecho de que la tradición se configure como modelo a seguir, para eso está, pero modelo ¿Para quién? En la década de los 50 , claramente, la gran tradición pictórica española (Velázquez, Ribera, Zurbarán, Goya) se impondrá como referencia de los pintores de vanguardia, especialmente en los ámbitos del informalismo, pero no siempre había sido así.

7 GAYA NUÑO, Juan Antonio, «Claves íntimas de la crítica de arte» (1960), Pequeñas teorías de arte, Madrid, Taurus, 1964.

8 MANZONI, Piero, «Prolegómenos para una actividad artística» (1957), citado en SAN MARTíN, Javier, Piero Manzoni, Hondarribia, Nerea, 1998. 
Las palabras de Juan de la Encina sobre el Greco podrían enfrentarse a otras que escribió, en 1940, Enrique Lafuente Ferrari, es verdad que están absolutamente condicionadas por el medio y las circunstancias en que se escribieron, que no son representativas del pensamiento historiográfico de su autor, que contrastan poderosamente con las críticas de alcance a las políticas artísticas del franquismo que Lafuente haría muy pocos años después, pero sirven, precisamente, para hacerse una idea de las circunstancias; "O teología o misterio -escribía Lafuente-, o Dios o Freud. El Greco supo de esto, por ello, canonizándole en el altar de las glorias españolas, anhelamos ante sus imágenes, en las que, como nunca en la historia del arte, lo sobrenatural cobra evidencia, esa nueva generación de santos para la que la tierra española debe estar de nuevo ya madura» ${ }^{9}$. El Greco, de quien Maurice Barrés escribiría que consiguió una identificación con España que, seguramente, no habría podido lograr un español de origen, parecía excesivamente moderno en la España de 1940, son dos formas contrarias de leer la gran tradición pictórica, ya se sabe como contribuyó Picasso a una nueva lectura del Greco o, como lo ha expresado Jaime Brihuega, «fue el 'Picasso azul' quien nos permitió interpretar definitivamente al Greco como anunciador de la sensibilidad moderna» 10 .

En 1955, Vicente Aguilera Cerni abordaba la obra del artista cretense desde planteamientos formales, afirmaba su condición de inspirador de la modernidad y se alejaba de esa visión militante; «anteponemos ante todo su profesión de fe pictórica, pues en él la causa es la pintura» ${ }^{11}$. Es esta visión que prioriza las formas la que hará de la tradición pictórica un modelo de modernidad.

Pero en los primeros de la posguerra española todo era distinto, José Aguiar abogaba en 1940 por la búsqueda de un estilo nacional como alternativa al desvío artístico de los dos siglos anteriores, no sólo para superar el arte de vanguardia, también para acabar con «el arte de mocita, abanico y cacharro talaverano»12, Gil Fillol escribía en 1943 un «responso al vanguardismo»13. Tomás Borrás recordaba, ese mismo año, a los artistas que «el sentido de la vida es cristiano, colectivo, heroico ${ }^{14}$. Samuel Ros afirmaba que de ninguna manera el arte de vanguardia puede servir para representar la nueva realidad española; «nos hubieran parecido muy bien los pintores cubistas para recoger la votación del Esta-

\footnotetext{
9 LAFUENTE FERRARI, Enrique, (1940), «El Greco, o la evidencia de lo sobrenatural», Vértice, 28, 1940.

10 BRIHUEGA, Jaime, «Constantes de modernidad en la tradición española. El Paso entre la herencia y la renovación», Chus TUDELILLA, El Paso a la moderna intensidad, Cuenca, Junta de Comunidades de Castilla-la Mancha, 2008, p. 65.

11 AGUILERA CERNI, Vicente, La aventura creadora. Ensayos sobre algunos aspectos en la creación artística, Valencia, Fomento de Cultura, 1955

12 AGUIAR, José, «Carta a los artistas españoles sobre un estilo», Vértice, 36, 1940.

13 GIL FILLOL, Luis, «Pasado y futuro del arte. Responso al vanguardismo», Gaceta de Bellas Artes, 459, 1944

14 BORRÁS, Tomás, “Conjeturas sobre artes plásticas», El Español, 10, 1943.

15 ROS, Samuel, «Arte y política», Arriba, 2 de julio de 1939, reproducido en Julián Díaz y Ángel Llorente, La crítica de arte en España (1939-1976), Madrid, Istmo, 2004.
} 
tuto catalán en el congreso y la huida de Dencás y entrega de Companys cuando la revolución del año 34 » $^{15}$.

Es muy interesante ver como se aborda el tema de la tradición, y otros, en el editorial del primer Suplemento de Arte de la exquisita revista Escorial, la plataforma más visible de los falangistas «liberales» ${ }^{16}$, algunos de los colaboradores de la revista tendrán un papel de gran interés en la renovación artística (Luis Felipe Vivanco, Dionisio Ridruejo, a través de Revista). Ahí se lamenta la pérdida de unidad espiritual en el arte español más reciente, pero la revista se compromete a ocuparse de él, sin amenazar con la depuración, desde el uso de «la más ambiciosa y bienintencionada crítica estética» ${ }^{17}$. El editorial distingue (en una posición bien distinta a las citadas en el párrafo anterior) entre una visión cultural y otra estrictamente artística del arte, ésta última le pondrá a salvo (la pureza, de nuevo); «las mejores tendencias del arte moderno nos han servido, al menos, para educar, de un modo sorprendente, nuestra sensibilidad de la pura materia plástica. Éste es un aspecto positivo suyo que, independientemente de toda ideología, y atentos a la calidad imprescindible de la obra de arte, no tendremos más remedio que reconocer y estimar en lo que vale» ${ }^{18}$, en fin, el arte de vanguardia es, a la larga, rehumanizable, o, lo que es lo mismo, reutilizable si se obvia su posible carga ideológica. $Y$ en cuanto a la tradición, «dentro del pasado está el gran arte español, cuya experiencia nos interesa de un modo especial. La existencia de ese arte español sin el cual no podría entenderse cabalmente el arte europeo ${ }^{19}$. Un arte que, más que impartir lecciones concretas, debe servir para dar temperamento al arte español actual. La gran tradición empieza a ser modelo de modernidad, sólo puede serlo desde la formulación de un arte despolitizado, una consigna que funciona frente a la vanguardia, desde luego, pero también frente a las formulaciones más conservadoras, que piensan en un arte del régimen, ante las que los falangistas «liberales» mostrarán una gran finura. El instrumento es claro; «creemos en la formación espiritual del artista como el único medio de conseguir que sus más precisas y privilegiadas instituciones creadoras se muevan dentro de un ámbito temático más amplio y profundo»20.

En su importante libro sobre la Bienal hispanoamericana de arte, Luis Felipe Vivanco menciona dos formas de entender el arte del pasado (no tan lejano como podría creerse, sino muy presente y vigente), los artistas académicos, explica el poeta, se atenían a fórmulas transmitidas, entendiendo que el arte antiguo era producto de una situación cultural diferente. Los artistas nuevos buscan la forma en la que «el arte del pasado es una realidad para el espíritu» ${ }^{21}$. A partir de esta idea,

16 Sobre el éxito de esta contradictoria expresión, véase JULIÁ Santos, “¿Falange liberal o intelectuales fascistas?", Claves de Razón Práctica, 121, 2002.

17 Anónimo, «Arte y espíritu», Escorial. Suplemento de Arte 1, 1942.

18 Ibídem.

19 Ibíd.

20 Ibíd.

21 VIVANCO, Luis Felipe, Primera Bienal Hispanoamericana de Arte, Madrid, Afrodisio Aguado, 1952, p. 13 
verdadera clave de bóveda de la modernización en el interior de España, la gran tradición pictórica cambiará de depositarios. Sabía bien por qué lo decía, la organización de la Bienal había dado lugar a agrios debates entre partidarios de la modernidad y de la tradición, repartidos en unas facciones que la propia Bienal y la literatura artística generada a su alrededor terminarían por romper ${ }^{22}$.

En un escrito tan interesante como citado, Ricardo Gullón sugirió que la pintura de Velázquez era un modelo de modernidad frente a los artistas académicos; la lección de Velázquez, decía, está «en los esfuerzo valientes y arriesgados de los pintores jóvenes ${ }^{23}$, es un síntoma de un cambio de paradigma historiográfico que lleva años en marcha para 1952 y que supondrá una recolocación de la gran tradición pictórica, que ya no es tanto un modelo como un estímulo, el patrón de los pintores académicos, dice Gullón en el escrito citado, no es Velázquez, será, en todo caso, Moreno Carbonero, toda una posición en un momento en que determinado sector de la crítica se desmarcaba de las Exposiciones Nacionales.

En 1949, la Revista de Ideas Estéticas, dirigida entonces por Camón Aznar, había publicado un artículo de Reynaldo dos Santos sobre Velázquez y un «Debate en torno al arte abstracto", un conjunto de textos recopilados por Rafael Santos Torroella, una contigüidad seguramente casual, pero de una rara coherencia. El artículo sobre Velázquez es la transcripción de una conferencia impartida el verano anterior en la Universidad Internacional Menéndez Pelayo, que ya para entonces empezaba a ser lugar de referencia en el debate artístico; allí, en 1953, tendría lugar «el reconocimiento oficial del arte abstracto»²4. En 1948 había tenido lugar la primera reunión de la escuela de Altamira, fue un año de febril actividad para el grupo Pórtico, que se había constituido en año anterior y en 1949 celebraría en Santander una de sus exposiciones de mayor alcance. El arte abstracto empieza, por tanto, a hacerse visible.

Lejos de una visión positivista, Reynaldo dos Santos incide sobre todo en la visión plástica del pintor, su sentido del color, la idea de la presencia del artista en los cuadros que niega la visión realista (entonces el término era bastante menos conflictivo que ahora). El argumento central es, desde el título, la subjetividad de Velázquez, la presencia de la pintura pura, la musicalidad, la necesidad de mirar sus cuadros pensando en las enseñanzas de Manet o de Matisse. Más que la captación fiel de la realidad viva, lo importante en Velázquez es «la irradiación de poesía, de humana melancolía, con las que ese ambiente velazqueño nos envuelve

22 CABAÑAS BRAVO, Miguel, La política artística del franquismo, Madrid, CSIC, 1996.

23 GULLÓN, Ricardo, "Semejanzas y diferencias en la Bienal», Cuadernos Hispanoamericanos, 26, 1952

24 BARCINO, Juan, «La decena de arte abstracto de Santander», La Vanguardia Española, 18 de agosto de 1953.

${ }^{25}$ SANTOS, Reynaldo dos, «El subjetivismo del arte de Velázquez», Revista de Ideas estéticas, 25, 1949, p. 17.

26 LAFUENTE FERRARI, Enrique, Ortega y las artes visuales, Madrid, Revista de Occidente, 1970. El libro recoge tres trabajos publicados en la década anterior, cuyos títulos merece la pena reproducir, «Las artes visuales y su historia en el pensamiento de Ortega», «Velázquez en Ortega y Gasset» y «Cuarenta años de deshumanización del arte». 
y nos conmueve» 25 . No es raro que el autor manifieste su deuda con Ortega, o con Lafuente Ferrari, que fue un excelente divulgador de las ideas histórico-artísticas del filósofo ${ }^{26}$. En realidad, dos Santos aplica la idea del cuadro como conjunto de manchas de color ordenadas de una determinada forma, la cita de Maurice Denis, tan repetida.

No debería sorprender, en este contexto, la propuesta, por parte de Santos Torroella, de un corpus de teoría sobre arte abstracto 27 . Aquí también hay algo así como una justificación por la tradición, ya que se mezclan unos textos recientes con otros más antiguos. Los de Kandinsky y el de Doerner se habían publicado en 1931 en la revista Cahiers d'Art, en el primero ${ }^{28}$, el pintor ruso contesta las acusaciones de cerebralidad y tendencia a lo geométrico que había formulado Christian Zervos contra él; como era de esperar, Kandinsky responde con una defensa de la espontaneidad y la intuición en la pintura, y de la necesidad de construir el arte desde el espíritu; «los artistas que se dan el nombre de constructivistas puros han realizado ensayos diversos para construir sobre una base puramente materialista ... cuando en la Escuela de pintura tenía que estudiar anatomía (a lo que no me inclinaba ninguna afición por ser pésima la enseñanza del profesor de la asignatura), mi maestro, Antón Azaba me decía 'los conocimientos anatómicos le son necesarios a usted, pero una vez ante el caballete tiene que olvidarlos' ... Tras el período del paisajismo, una vez admitido éste, la prensa, el público y los artistas mismos se estremecieron de nuevo cuando, de pronto, se empezaron a pintar cada vez en mayor medida 'naturalezas muertas'. El paisaje, al menos, es algo vivo (naturaleza viva), se decía entonces y por algo se le llama a este otro género 'naturaleza muerta'. [La abstracción] no excluye en modo alguno la ligazón con la naturaleza, sino al contrario, que esta ligazón es mayor y más íntima de lo que fue en los últimos tiempos»29. El texto, por tanto plantea una idea que va a ser de gran utilidad en la España de posguerra, el arte abstracto presupone, subsume, los grandes géneros pictóricos, no hay contradicción si el arte se ha producido de modo espontáneo, si es producto del espíritu. Dentro de una pintura abstracta hay, al menos en la evocación, una figurativa.

Alfred Doerner planteará la abstracción como algo inevitable, e históricamente explicable; es el culmen de un proceso de ruptura del espacio renacentista, de la concepción del cuadro como ventana abierta al mundo de lo visible, que comienza en el romanticismo y posee un jalón importante en el cubismo; «La pintura es el reflejo de las representaciones de la realidad que se representa cada época» ${ }^{30}$. El abandono de la representación, ligada al punto de mira en perspectiva, propicia la desaparición del marco del cuadro; «la materia deja de concebirse como una masa opaca».

27 SANTOS TORROELLA, Rafael (ed.), «Debate en torno al arte abstracto (W. Kandinsky, Alexander Doerner, Lionello Venturi, André Lhote, Herbert Read y Víctor Servranckx)", Revista de Ideas Estéticas, 25, 1949.

${ }^{28}$ Los textos se publicaron en Cahiers d'Art, 7-8, 1931, el primero «Reflexiones acerca del arte abstracto» se reproduce en W. KANDINSKY, Gramática de la creación. El futuro de la pintura, Bacelona, Paidós, 1987 (1970).

29 KANDINSKY, «Reflexiones acerca del arte abstracto», Revista de Ideas estéticas, op. cit. 
Los textos restantes, del año 1948, reflexionan sobre aspectos que van a estar muy presentes en la crítica. Lionello Venturi niega que exista una separación radical entre los términos «realismo» y «abstracción»; «los verdaderos artistas de tendencias realistas no imitan la naturaleza exterior, sino que representan la naturaleza del hombre ... Resulta evidente que toda obra de arte constituye una abstracción y que siempre ha sido así ... permaneciendo fiel el pintor realista a los datos inmediatos de la conciencia, mientras que el pintor abstracto se interesa, sobre todo, por la elaboración de la fantasía más allá de estos datos inmediatos» ${ }^{31}$.

Como no podía ser menos, Lhote defiende en su texto la vigencia del cubismo, Read entendía la oposición entre realismo y abstracción como una tensión entre contrarios y reivindicaba, en todo caso, la libertad del artista, Servranckx subrayaba el potencial de transformación del arte abstracto.

Todos los textos confirman la idea de que el arte abstracto es menos rupturista de lo que pueda parecer, que hay menos distancia de la que los académicos marcan entre la pintura clásica y la pintura abstracta, que el dilema entre figuración y abstracción tiene poco sentido frente a la necesidad de que el arte sea auténtico y coherente con su tiempo. Y que, al fin, el arte abstracto (no geométrico), espontáneo, pasional, se presenta como un factor de pureza, de salvación del arte, porque, en definitiva, mantiene algunos de sus principios inmutables, presupone, más que otras propuestas de vanguardia, una tradición.

Lo explicaba con claridad Lafuente Ferrari en 1950, en un escrito interesante sobre la génesis de la pintura contemporánea ${ }^{32}$, una historia que, salvo por episodios como el expresionismo y el surrealismo (que el historiador condena sin paliativos), nos recuerda que «sin espíritu no hay arte». La pintura contemporánea nace tras el impresionismo (como había escrito Eugenio d'Ors en su conocido Mi salón de otoño) y se interesa sobre todo por problemas de construcción, ordenación, composición y, en general prioriza los valores plásticos frente a la anécdota, en el fondo no hay nada nuevo; "esos principios, defendidos por los pintores de vanguardia en nuestro tiempo, son, en realidad, eternos; es decir, inherentes a la obra de arte en cuanto lo sea. En Rafael, en el Greco, en Velázquez, hay, indudablemente, arabesco, composición y valor sustantivo de lo plástico. La reacción se engendró contra la monótona tiranía de las escuelas del siglo XIX, contra el naturalismo prosaico y aquel espíritu positivista del realismo que ponía como imperativo esencial la exactitud, esa exactitud documental en la que el pintor o el escultor no podrían rivalizar con la fotografía»33.

30 DOERNER, Alfred, «Consideraciones sobre la significación del arte abstracto», Santos Torroella, «Debate..., p. 84.

31 VENTURI, Lionello «Realismo y abstracción», Santos Torroella, «Debate..., op. cit.

32 LAFUENTE FERRARI, Enrique, «Sobre el proceso y los supuestos de la pintura contemporánea» (1950), El arte de hoy, Torrelavega, Cantalapiedra, 1955

33 Ibídem, p. 13.

34 Nos ocupamos de este tema en DÍAZ SÁNCHEZ, Julián, El triunfo del informalismo. La consideración de la pintura abstracta en la época de Franco, Madrid, Metáforas del Movimiento Moderno, 2000. 
Los escritos sobre arte de Ortega y Gasset pueden verse como telón de fondo a esta relectura de la tradición ${ }^{34}$. Aguilera Cerni sostuvo que la publicación, en 1950, de sus Papeles sobre Velázquez y Goya fue un hito en la percepción del arte español, que tuvo puntual reflejo en la crítica ${ }^{35}$, también en la historia. Aguilera no deja de recordar, en este interesante trabajo que, en los años 20, Ortega dirigía la colección «Biblioteca de Ideas del siglo XX», que publicaría La decadencia de Occidente de Spengler, con la que su influyente trabajo La deshumanización del arte tiene ciertas similitudes ${ }^{36}$, las ideas de Ortega con respecto al arte son multidireccionales. Sólo subrayaremos la responsabilidad de Ortega en la visión moderna de Velázquez $z^{37}$ y de Goya, «padre de todo el arte moderno», había señalado Joaquín Ruiz Giménez en el discurso de inauguración de la I Bienal Hispanoamericana de Arte en 1951. En fecha tan temprana como 1912, Ortega había escrito un texto en el que cuestionaba seriamente el término realismo y, de paso, su aplicación a la pintura velazqueña ${ }^{38}$.

En Ortega, la fabulación del «monstruo Goya» ${ }^{39}$ constituye, por sí misma, todo un tópico en la crítica y la historiografía artísticas. Ortega afirma que hay que imaginar a Goya, más que analizarlo, y unificar toda su obra; el filósofo negará, además, la condición de populista y castizo que se ha atribuido al artista aragonés. El arte de Goya es una muestra de deshumanización, la esencia de su estilo radica en la «falta de humana simpatía por los seres que pinta ... En sus composiciones al entrar el ser humano queda ipso facto convertido en un muñeco perfectamente canjeable por otro ... El protagonista es el cuadro mismo" ${ }^{40}$.

Su resistencia al desarrollo de una historia del arte nacionalista, desde la idea de que la gran pintura española debe reducirse, en realidad a Ribera, Zurbarán, Alonso Cano y Velázquez y considerarse como un apéndice de la pintura europea, dio también algunas pistas a críticos e historiadores del arte, aunque contraste claramente con la consideración de los cuadros de Zuloaga como «ejercicios espirituales que nos empujan, más que nos llevan, a un examen de conciencia nacional» ${ }^{41}$. Pero en general, en Ortega queda clara la idea de una tradición como modelo de modernidad. La idea de que los problemas estéticos son los mismos en

35 AGUILERA CERNI, Vicente, Ortega y d'Ors en la cultura artística española, Madrid, Ciencia Nueva, 1966.

36 Ibídem, p. 67.

37 Ortega recordará el hecho de que Velázquez y Descartes sean coetáneos: «sorprenderá la advertencia -y la hago precisamente para producir cierto choc en el lector- de que a esta generación pertenece también Descartes, 1596». José ORTEGA Y GASSET, Papeles sobre Velázquez y Goya, Madrid, Alianza, 1980, p. 13. Las implicaciones de tal coincidencia cronológica fueron estudiadas por MARAVALL, José Antonio, Velázquez y el espíritu de la modernidad, Madrid, Guadarrama, 1960 (reed. en Madrid. Alianza. 1987). La cercanía de ambos análisis se subrayó en BOZAL, Valeriano, "José Ortega y Gasset», Historia de las ideas estética y de las teorías artísticas contemporáneas, Mdrid, Visor, 1996.

38 ORTEGA Y GASSET, José, «Del realismo en pintura». El sentimiento estético de la vida (Antología), Madrid, Tecnos, 1995, ed. de José Luis Molinuevo, pp. 157-160.

39 ORTEGA Y GASSET, José, «Preludio a un Goya», Papeles sobre Velázquez y Goya (1950), op. cit., p. 279.

40 lbídem, p. 290. 
Velázquez y en los artistas abstractos tiene un papel fundamental en el éxito de la abstracción en los años 50.

\section{RELEER EL PASADO. LOS ARTISTAS}

Tàpies se consideró heredero de Miró, aunque sus opciones más concretas fueran otras, y así lo hizo saber en más de una ocasión. En 1955, desde una afirmación de individualidad e independencia, Tàpies evocaba la presencia discreta pero evidente de Joan Miró en la Barcelona de posguerra, donde será una referencia para Dau al Set, grupo al que, en su conferencia, Tàpies reduce a «un pequeño boletín medio confidencial» ${ }^{42}$. Miró sería también un referente para Pórtico, aunque la lectura del artista que hacía el grupo era diferente de la de Dau al Set, más parecida a la que hizo la Escuela de Altamira, en cuyo ámbito se pensaba que el surrealismo había sido, en la obra de Miró, algo provisional, accesorio y que su obra iba más allá de los supuestos del movimiento de Breton; incluso, como escribió Ricardo Gullón, que el regreso de Miró a España había supuesto un cambio que iba de lo surreal a lo ancestral (que parece triunfar siempre); «Velázquez y Miró, tan lejanos entre sí, están en la misma línea o, si se prefiere, en el mismo plano, con predominio de los elementos de contención, mientras los románticos se instalan en otros ${ }^{43}$, parece haber un amplio acuerdo en minimizar el sentido surrealista en Miró; «tiene razón Cirlot cuando afirma que Miró es un solitario y que su pintura no encaja en los límites estrechos, y con frecuencia extra pictóricos, del surrealismo ${ }^{44}$.

No estará de más recordar que Clement Greenberg escribió, en 1945, que Jackson Pollock habría sido «el mejor desde Miró» ${ }^{45}$. Como dice T. J. Clark, «el arte quiere dirigirse a alguien ${ }^{46}$ y en esa medida comporta siempre una visión del pasado. Situarse significa también reescribir el pasado; «Un pintor moderno — desde luego en la época de Courbet y la de Manet, pero por qué no también en la de Pollock o Richter - intenta establecer una comparación con aquella pintura del pasado cuya calidad le parece incuestionable en la misma medida en que no deja de ponerla en cuestión y de socavarla con sus provocaciones» ${ }^{47}$. Así la pintura del pasado puede convertirse en un mecanismo de protección.

41 ORTEGA Y GASSET, José, “¿Una exposición Zuloaga?”, La deshumanización... op. cit., p. 62.

42 TÀPIES, Antoni, «La otra pintura», Cuadernos Hispanoamericanos, 70, 1955, p. 21

43 GULLÓN, Ricardo, «Juan Miró, por el camino de la poesía», De Goya al arte abstracto, Universidad de Puerto Rico, 1963.

44 LAFUENTE FERRARI, Enrique, «Miró o la pintura en libertad», Papeles de Son Armadans, 21, 1957, p. 299.

${ }_{45}$ Citado en DUVE, Thierry de, Clement Greenberg entre líneas, Madrid, Acto Ediciones, 2005, p. 21

${ }^{46}$ CLARK, T. J., "Clement Greenberg's Theoric of Art», FRASCINA, Francis, Pollock and after, London, Harper Row, 1985.

47 DUVE, Thierry de, o. cit, p. 81-82.

48 BOZAL, Valeriano, El tiempo del estupor, Madrid, Siruela, 2004, p. 13. 
Las opciones artísticas de posguerra parecen tener como referencia un mundo "que parece no poder ser dicho» ${ }^{48}$, consecuencia de la teórica imposibilidad de crear después de Auschwitz que invocaba Adorno, quien, no obstante, afirmó que «la situación ya no consiente el arte (a esto se refería la frase sobre la imposibilidad de los poemas después de Auschwitz) pero lo necesita» ${ }^{49}$. Así que no se prescinde de la tradición, aunque pueda parecerlo, aunque se invoque una vuelta a los orígenes, una más.

Antonio Saura suscribió, en la práctica, la lección de Ad Reinhardt, que consideraba el arte abstracto como un mecanismo fundamental de salvación del arte; así lo dejó entrever en uno de sus textos más conocidos, que empieza explicando que la consideración del cuadro como objeto bidimensional supone "una de las grandes conquistas plásticas del siglo $X X{ }^{250}$. Es el espacio vacío el verdadero protagonista del cuadro, no las formas. No es una idea muy diferente a la que enuncia Greenberg para explicar el proceso de la pintura moderna; «no es por principio que los pintores modernos de la última época han abandonado la presentación de objetos reconocibles. Lo que han abandonado es la representación del tipo de espacio que ocupan los objetos reconocibles ${ }^{51}$.

Del texto de Antonio Saura podríamos deducir un esquema no muy diferente del de Alfred $\mathrm{H}$. Barr ya citado, un árbol. La historia es, más o menos, así: el cuadro bidimensional comienza con las propuestas expresionistas y fauves, aunque se insinúe en el impresionismo, pero la nueva estructuración del cuadro depende del cubismo analítico (Picasso y Braque) y de la obra de Kandinsky, Klee y Miró. A partir de aquí, se confirma una nueva, y definitiva, configuración del cuadro en Tobey, Dubuffet, Still, Rothko y Pollock, donde los protagonistas de la pintura son, por vez primera, el espacio y el gesto.

La posguerra (europea) expresa una pugna entre pintura abstracta constructiva y expresiva; la primera, geométrica, la segunda, espacio-gestual, una tercera vía (Soulages, Stael) deja notar la presencia de las estructuras tradicionales en el cuadro. Es la segunda la que se plantea como una verdadera transformación, tanto en la corriente de Fautrier, Dubuffet y Wols que conforman un verdadero espacio-materia que se presenta como una particular visión del cosmos que, no obstante, enlazará con el pasado; «en algunos pintores europeos, bajo formas de cósmica y barroca síntesis y especialmente en los españoles, de una verdadera ascesis de color y expresión, de telúrica violencia, el cuadro queda organizado en una materia-espacio de oculta estructuración en contraposición a otros artistas que trabajan utilizando técnicas más tradicionales» ${ }^{52}$. En los pintores gestuales, el gesto es un campo de acción («la

49 ADORNO, T. W., Crítica de la cultura y la sociedad I, Madrid, Akal, 2008, p. 396.

50 SAURA, Antonio, "Espacio y gesto», Papeles de Son Armadans, XXXVII, 1959.

51 GREENBERG, Clement, «La pintura moderna» (1960), La pintura moderna y otros ensayos, Madrid, Siruela, 2006, ed. de Félix Fanés, p. 114.

52 SAURA, Antonio, «Espacio y gesto», op. cit, p. 52. 
tela es un campo de batalla», escribirá Saura en un texto de la misma época), una ocupación y, en definitiva, una afirmación de la presencia del artista.

Al contrario que los expresionistas de la primera mitad del siglo, o los casos aislados como el Greco, Goya o Van Gogh, en el expresionismo abstracto las formas son deshechas y rehechas, éste es el fundamento de algunos pintores matéricos como Burri, Tàpies o Millares, que evocan la idea de creación y destrucción, y esa es la razón por la que algunos pintores pueden ser observados desde dos enfoques figurativo y abstracto, una constante y un dispositivo permanente de anclaje con la tradición. No es tanto una vuelta a la imagen como «una forma inédita de enfocar la realidad».

Como dice Tapié (y parece suscribir Antonio Saura), «el problema no consiste en sustituir un tema figurativo por una ausencia de tema, llámese abstracto, no figurativo o no objetivo, sino en hacer una obra, con o sin tema, ante la cual, cualquiera que sea la agresividad o la banalidad del contacto epidérmico, nos demos cuenta poco a poco de que dejamos de hacer pie, de que vamos a entrar en éxtasis o en demencia»53. Los pintores del silencio y los de acción, escribe Saura, «hunden al espectador»; el resultado es un vacío ilimitado que tiene precedentes en la pintura china $^{54}$, en las últimas pinturas de Monet o en las marinas de Turner. Al fin, se articula una relación dramática entre el expresionismo abstracto y su época.

«El expresionismo abstracto lleva en su entraña la dosis más imponente de energía que el arte nos haya ofrecido hasta la fecha. Barroco tumulto en el que, sin embargo, existe una matemática interna, intuitiva, que hace que un gesto vaya justificado por el anterior, en fatal ligazón, creando una serie de reacciones en cadena que finalizan en un momento dado ${ }^{55}$. Hay, frente a lo que pueda parece a primera vista, un plan, no sorprende el uso del término «barroco» en esta reafirmación de la pintura que parece querer poner, como en la época barroca, la pintura entre el espectador y la realidad ¿pintar a lo valiente?

La pintura informalista plantearía una ruptura con los últimos reductos del humanismo clásico, sería el fin de un proceso de dos siglos, una proposición de libertad total, y un proceso de renovación. Sería esta pintura un acto de nihilismo, un grito hermoso entre tanto desastre.

En 1963, en un libro de referencia, José María Moreno Galván escribió algo que podría ser un corolario al texto de Antonio Saura; «el aformalismo es la sustitución del arte por la vida» ${ }^{56}$, el crítico sugería también la presencia de un nuevo tipo de artista que estableció una relación diferente con la tradición, menos polé-

53 TAPIÉ, Michel, Un art autre (1952), citado en LORENTE, Jesús Pedro, Historia de la crítica de arte. Textos escogidos y comentados, Prensas Universitarias de Zaragoza, p. 434.

54 Sobre el posible origen en la pintura china del logotipo del grupo El Paso, véase TUDELILLA, Chus, El paso a la moderna intensidad, Cuenca, JCCM, 2009, p. 21.

55 Antonio SAURA, «Espacio y gesto», Papeles de son Armadans, 37, 1959, p. 55.

56 MORENO GALVÁN, José María, Autocrítica del arte, Sevilla, Barataria, 2010 (1963), p. 30.

57 Ilbídem p. 33. 
mica y menos política; «en contraste con él [el artista de vanguardia clásica], el aformalista es un hombre que ha recuperado el sentido de la mesura y de la convivencia: venera a los maestros del pasado, no siente la necesidad de denigrar a las eminencias del presente ${ }^{57}$.

El texto de Antonio Saura es el primero de un conjunto de escritos de artista que publicó la revista Papeles de son Armadans, que dirigía Camilo José Cela desde Palma de Mallorca, en un número monográfico dedicado al grupo El Paso en vísperas de su disolución, se trata de la primera aproximación canónica al grupo, un año después del triunfo del informalismo en la Bienal de Venecia y en un momento en que menudeaban los éxitos y, hay que recordarlo, crecía la incomodidad de algunos artistas que pronto decidirán no participar en exposiciones oficiales del régimen, pero éste es otro asunto. En los textos citados hay una recurrencia constante a la tradición que no parece ser sólo estratégica, sino que tiene que ver con esa conversión de la tradición pictórica en modelo de modernidad, que, a su vez, tiene que ver con una visión del arte abstracto como arte estético (que diría Ortega), expresivo, provocador, pero finalmente estético, autorreferencial.

Manuel Viola había regresado a España en 1949, después de un exilio en París, su obra se había incluido en la exposición de artistas españoles en Praga, de $1946^{58}$. Viola negaba que el arte fuera una «medio de expresión»59; arte, decía, es un término que provoca nauseas por lo que encierra de «acomodaticio, adormecedor y evasivo". Se manifestaba contrario a toda forma de esteticismo, o decorativismo y, de manera explícita, hacía de Goya un profeta del Informalismo, anticipado en las pinturas negras, algo que se nota en sus Saetas de esta época. Viola terminaba su programa con una firme y clarificadora declaración de intenciones: «Estamos con lo que es condición humana, contra un arte que niega la vida, por un 'arte otro', un 'arte además' y si es necesario por el anti-arte»60.

Rafael Canogar, el componente más joven del grupo EL PASO, atribuía a su pintura una función muy concreta: «encontrar nuevamente las verdaderas esencias de la pintura española de todos los tiempos" ${ }^{61}$. El pintor defiende la improvisación, que se concreta sobre todo en la utilización directa del tubo de pintura; sin embargo, explica, las informas están condicionadas «al impulso que crea el estilo de una época». Defiende un estilo de aspecto caótico, que debe esperar la separación entre abstracción y figurativismo, enfocando la realidad desde un ángulo diferente. Como se sabe, Canogar abandonó pronto el informalismo en aras de una figuración entre el realismo crítico y el pop, para volver después a una abstracción muy

58 TUSSEL, Javier, y Álvaro MARTíNEZ NOVILLO, Artistas españoles de París-Praga 1946, Madrid, Cala de Madrid, 1993.

59 VIOLA, Manuel, «Anti-arte», PAPELES DE SON ARMADANS, núm. 37, op. cit., pp. 67-69.

60 Ilbídem p. 69.

61 CANOGAR, Rafael, «Tener los pies en la tierra», PAPELES DE SON ARMADANS, núm. 37, op. cit., p. 70. 
ordenada. En 1984 Canogar justificaba su escape del informalismo por agotamiento del movimiento y daba una definición interesante:

«El informalismo ... Es una obra que está basada en la expresión instantánea de sentimientos, era echar fuera sin pasar por el filtro de la razón los fantasmas que uno pudiera llevar dentro, y ese gesto existencial, esa tensión, no se puede mantener durante años, tiene una vitalidad corta ... No se puede mantener durante años sin que se convierta en retórica» ${ }^{2}$.

Manuel Rivera ${ }^{63}$ defendía la improvisación en un argumento que recuerda claramente los de la escritura automática y que, por lo tanto, podríamos considerar de adscripción surrealista aunque el término no se mencione. Como el arte no es una cosa mental uno no puede acercarse al cuadro con ideas preconcebidas. Martin Chirino ${ }^{64}$ plantea, por su parte, la cercanía entre su obra y herramientas como la reja o el arado que vinculan al hombre con la tierra en una clara alusión a lo que podría ser el arte popular.

La interpretación dramática del arte es especialmente evidente en Saura (ya lo hemos visto) y en Millares; Papeles publicaba uno de los textos más conocidos del segundo ${ }^{65}$, que además ha servido tradicionalmente en el análisis de su pintura. El texto se mueve entre la declaración de intenciones y la interpretación histórica, en el primer aspecto se enuncia la idea la idea (repetida hasta la saciedad) de que «el arte sabe levantar pústulas hasta ahora ocultas en hipocresías». En el segundo el inevitable enlace con Goya, después del cual «Sólo nos queda la auténtica vía social de los despojos materiales, el florecimiento del homúnculo como insidioso arquetipo ${ }^{66}$.

Desde esta perspectiva el homúnculo sería un fenómeno del arte contemporáneo y no, como cabría esperar, de la pintura del propio Millares. El homúnculo está en la tradición del monstruo picassiano y de la afición de nuestro tiempo a las formas orgánicas, presentes en grupo en la obra de Pollock, como esperpentos en De Kooning, pero también en Dubuffet, en Appel o en Fautrier, sin olvidar las metamorfosis de Saura que convierte al sexo femenino en auténtica Venus ibérica de la misma fealdad. El homúnculo no es sólo una manifestación contemporánea, forma parte de las tradiciones españolas y, por eso, concede carta de naturaleza trágica a la pintura informalista: «Presentar las cosas con pelos y señales ... sacar la momia de su saco, el gusano asqueroso de su sitio; traer a secar los ataúdes reales a un sol de sombras humedecidas bajo el gran catafalco. Matarle la sonrisa

62 RUBIO, Pilar, «El eterno retorno. Entrevista con Rafael Canogar», LAPIZ, núm. 16, Madrid, mayo de 1984 , pp. $30-36$.

63 RIVERA, Manuel, «La tela de araña», PAPELES DE SON ARMADANS, núm. 37, op. cit., pp. 7374.

64 MARTIN CHIRINO, «La reja y el arado», PAPELES DE SON ARMADANS, núm. 37, op. cit., pp. 77-78,.

65 Manolo MILLARES, «El homúnculo en la pintura actual», PAPELES DE SON ARMADANS, núm. 37, op. cit., pp. 79-83

66 Ilbídem p. 80. 
campechana a Juan Ruiz. Actualizar la sucia amenaza que creó Gaspar Becerra ${ }^{67}$. El enlace con el pasado es evidente.

Millares acudirá con frecuencia a la tradición; en 1960, la Sala Gaspar organizó la exposición O Figura. Homenaje informal a Velázquez, para la que Millares (que afirmaría que no le gustaba demasiado Velázquez) escribió, además de aportar algunas obras, lo siguiente: «Una razón en mi interés hacia Velázquez puede ser aquél abultamiento nervioso de sus vestimentas bajo y sobre las cuales ya nos guiña el ojo negro la rabia incontenible del pintor de Fuendetodos", y a continuación, a modo de explicación menos pública, explica: «Total, nada. Sale uno de Goya y se vuelve a meter en Goya»68. En otras ocasiones Millares, como otros artistas del Paso, situó al grupo en los parámetros de la tradición ${ }^{69}$.

\section{EL RESPALDO DE LOS CRÍTICOS}

La recurrencia de los críticos a la tradición pictórica española es tan frecuente y decidida que no puede ser casual. Encadenemos, de nuevo, algunos ejemplos; Juan Eduardo Cirlot veía «espacios descoyuntados de Ribera y flagelantes de Goya» en la pintura de Canogar ${ }^{70}$; los cuadros de Feito tenían, para Manuel Sánchez Camargo, «un antecedente en los maestros españoles y nos llevan a pensar en Zurbarán " ${ }^{71}$. Para Sancho Negro (un pseudónimo que utilizó con frecuencia Manolo Millares, de nuevo) Saura era «posiblemente el pintor más español de nuestros días junto a Picasso ... austero como Zurbarán, barroco como Theotokopoulus, picaresco como el de Hita, de la mano de Goya»72.

La posición de los críticos queda clara en La pintura informalista española a través de sus críticos, un libro colectivo que publicó en 1961 la Dirección General de Relaciones Culturales, el conjunto de tópicos que reúne el libro constituye, sin duda, una parte importante del relato oficial del Informalismo. Que comience con un texto sobre Isidre Nonell no es casual ni nuevo; casi todos los relatos sobre arte español del siglo XX empiezan por ahí, Mi Salón de Otoño, escrito por Eugenio d'Ors en 1924, el Primer Salón de los Once, la exposición Precursores y Maestros de la I Bienal Hispanoamericana de Arte y la Colección de Arte Español del MNCARS, Nonell ha sido siempre un curioso referente de modernidad.

\footnotetext{
67 Manolo MILLARES, «El homúnculo en la pintura actual», op. cit., p. 82.

68 Las dos citas en «De Millares a Westerdahl, 19 de septiembre de 1960», El artista y el crítico. Manolo Millares y Eduardo Westerdahl, correspondencia 1950-1969, Madrid, La Fábrica, 2011, edición crítica de José Luis de la Nuez Santana, p. 181.

69 MILLARES, Manuel, «El Paso: sobre el arte de hoy en España», Arte vivo 1, segunda época, 1959. Ahora en RAMÍREZ, Pablo, Grupo Parpalló. 1956-1961, Valencia, Generalitat Valenciana, 2006.

70 CIRLOT, Juan Eduardo, «La pintura de R. Canogar», Índice de Artes y Letras, 136, 1960.

71 SÁNCHEZ CAMARGO, Manuel, «Feito», Pueblo, 31 de octubre de 1958, p. 10.

72 SANCHO NEGRO, «Saura», Punta Europa, 25, 1958, pp. 130-131.
} 
La pintura informal admite una visión mística; «el fuego del arte abstracto ha prendido con fuerza en tierras de España. Sus llamas (...) algo nuevo anuncian al mundo con la gravedad de su religioso sentir, con el aliento poderoso de su anhelo místico, con su personal sentir de la vida» ${ }^{73}$, son palabras de Alfonso Roig; Carlos Areán decía que la pintura española es la más rica cromáticamente, pero también la más contenida, y el Informalismo seguirá fiel a esas tradiciones cromáticas que, como decía José Ayllón a propósito de la pintura en blanco y negro, no suponen sólo austeridad, sino descarga de una tensión emocional ${ }^{74}$. Como el tenebrismo, un referente, una determinación del carácter español que conduce a la gravedad, al equilibrio, a la proporción expresiva ${ }^{75}$. O la materia: «la pintura española es trágica (...) por el mero hecho de que la materia que usa es trágica en su misma naturaleza» ${ }^{76}$ ¿habrá que recordar que en 1960, Frank O’Hara escribió que la pintura de Millares poseía la elegancia del torero?

Pintura y crítica contribuyeron, en la España de posguerra, a una determinada construcción del pasado (cada época produce las suyas), en ésta se excluyó a la vanguardia de entreguerras (sobre todo en sus manifestaciones más políticas) y se llevó a cabo un enlace con la gran tradición pictórica española que, de Velázquez a Goya, se vio como un modelo de modernidad. Fue (aunque no lo pareciera siempre) mucho más que una estrategia.

73 ROIG, P. Alfonso, «La mística en el arte español», La pintura informalista española a través de sus críticos, Dirección General de Relaciones Culturales, Madrid, 1961.

74 AYLLÓN, José, «La pintura en blanco y negro», Papeles de Son Armadans, 37, 1959.

75 CASTRO ARINES, José, «Tenebrismo», La pintura informalista, op. cit.

76 POPOVICI, Cirilo, «La pintura española de los nuevos materiales», La pintura informalista, op. cit. 
